University of Louisville

ThinkIR: The University of Louisville's Institutional Repository

\title{
The effect of the blue light diode laser on shear-peel bond strength of orthodontic brackets with varying curing time and distance.
}

Kamran Shaikh 1978-

University of Louisville

Follow this and additional works at: https://ir.library.louisville.edu/etd

\section{Recommended Citation}

Shaikh, Kamran 1978-, "The effect of the blue light diode laser on shear-peel bond strength of orthodontic brackets with varying curing time and distance." (2010). Electronic Theses and Dissertations. Paper 1309. https://doi.org/10.18297/etd/1309

This Master's Thesis is brought to you for free and open access by ThinkIR: The University of Louisville's Institutional Repository. It has been accepted for inclusion in Electronic Theses and Dissertations by an authorized administrator of ThinkIR: The University of Louisville's Institutional Repository. This title appears here courtesy of the author, who has retained all other copyrights. For more information, please contact thinkir@louisville.edu. 
By Kamran Shaikh

BSc University of Toronto, 2001

DDS New York University College of Dentistry, 2005

\author{
A Thesis \\ Submitted to the Faculty of the \\ Department of Orthodontics \\ University of Louisville School of Dentistry \\ In Partial Fulfillment of the Requirements \\ For the Degree of
}

Masters in Oral Biology

August 2010 


\title{
THE EFFECT OF THE BLUE LIGHT DIODE LASER ON SHEAR-PEEL. BOND STRENGTH OF ORTHODONTIC BRACKETS WITH VARYING CURING TIME AND DISTANCE
}

\author{
By \\ Kamran Shaikh \\ BSc University of Toronto, 2001 \\ DDS New York University College of Dentistry, 2005
}

A Thesis Approved on

June 17, 2010

By the following Thesis Committee

Sunita Chandiramani, DMD, MS

Thesis Director

David Tasman, DMD

Baxter E. Johnson, DDS, MS 


\section{DEDICATION}

This thesis is dedicated to my family, who have instilled in me the values of education and giving me the opportunity to pursue my goals. A special thanks to my wife, Zarina Shaikh, for all of her support and understanding throughout. 


\section{ACKNOWLEDGEMENTS}

I would like to thank all of my committee members, Dr. Sunita Chandiramani, Dr.

David Tasman and Dr. Baxter E. Johnson for all of their aid and guidance that they have provided in developing this study. I would also like to acknowledge Alex Cambon for his work and help in developing a statistical protocol for analyzing this data. A special thanks to Dr. Richard Mitchell of the University Of Kentucky College Of Dentistry for all of his time and use of his equipment. Also would like to express my gratitude to $3 \mathrm{M}$ Unitek for donating all of the brackets that were used in this study. 


\begin{abstract}
THE EFFECT OF THE BLUE LIGHT DIODE LASER ON SHEAR-PEEL BOND STRENGTH OF ORTHODONTIC BRACKETS WITH VARYING CURING TIME AND DISTANCE

Kamran Shaikh, DDS

June 17, 2010
\end{abstract}

Background: Light cured composite resin can be time consuming for bonding orthodontic brackets. A new Blue light diode laser may reduce curing times for composite resins. Hypothesis: The laser will achieve similar bond strengths in half the time and at greater distances as the LED. Methods: 90 extracted premolars will be bonded and cured using Laser and LED curing units at varying times, another 120 extracted premolars will be bonded and cured at varying distances. An Instron machine will be used to test shear bond strength. Results: The laser was not able to achieve similar bond strengths as the LED curing light in half of the curing time. At 5 seconds, the laser had $35 \%$ lower bond strengths but was still in the clinically acceptable range. The laser achieved similar bond strengths when the curing tip was at greater distances as when it was close to the bracket-adhesive-tooth interface. 


\section{TABLE OF CONTENTS}

PAGE

ACKNOWLEDGEMENTS ............................................................

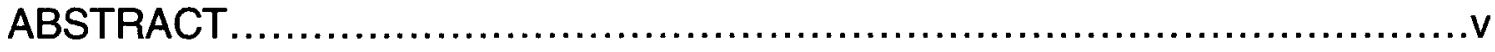

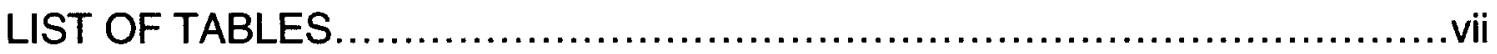

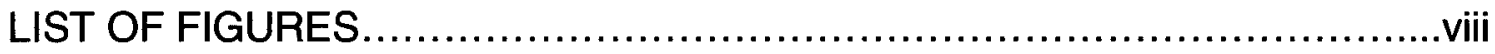

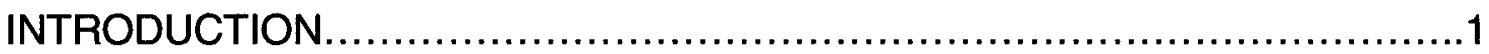

METHODS AND MATERIALS ................................................ 14

BOND STRENGTHS OF BRACKETS CURED WITH VARYING TIME.......15

BOND STRENGTHS OF BRACKETS CURED WITH VARYING DISTANCE.......21

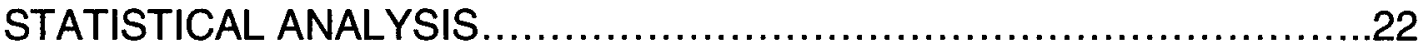

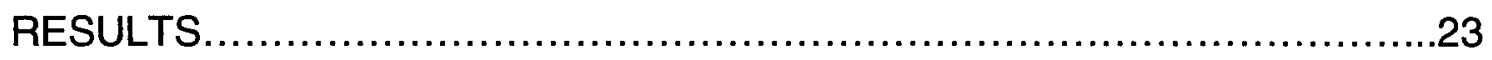

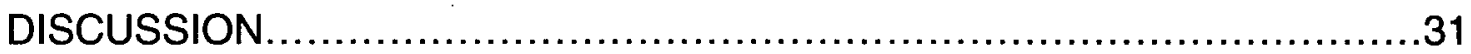

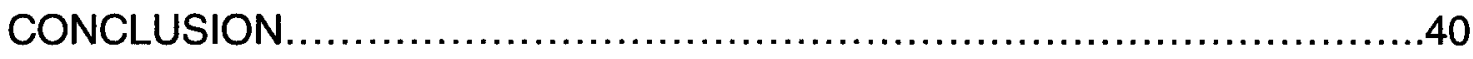

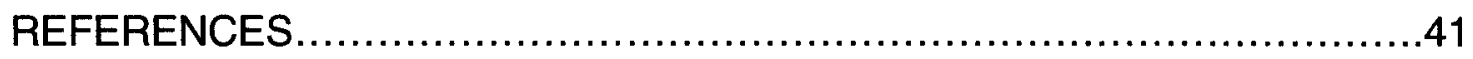

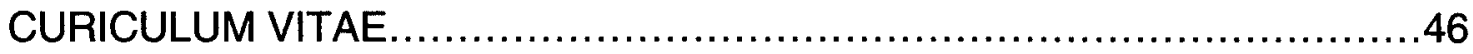




\section{LIST OF TABLES}

TABLE

PAGE

1. Bond Strengths with Varying Curing Times..................................23

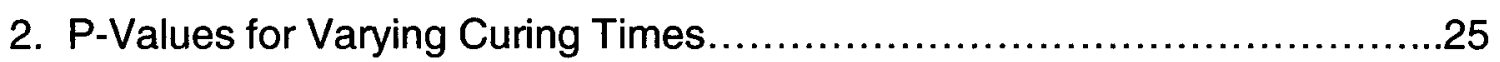

3. ARI for Varying Curing Times...................................................25

4. Comparison of Varying Curing Distances Cured for 5 seconds................26

5. Comparison of Varying Curing Distances Cured for 10 seconds.............27

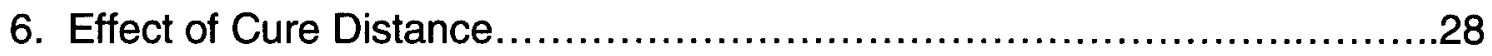

7. ARI for Varying Curing Distance Cured for 5 seconds ......................29

8. ARI for Varying Curing Distance Cured for 10 seconds.......................30 


\section{LIST OF FIGURES}

FIGURE

PAGE

1. Aquarius Blue Light Diode Laser.........................................17

2. Dental Surveyor to Level Bracket Wings ....................................18

3. Dental Surveyor to Parallel Long axis of tooth................................18

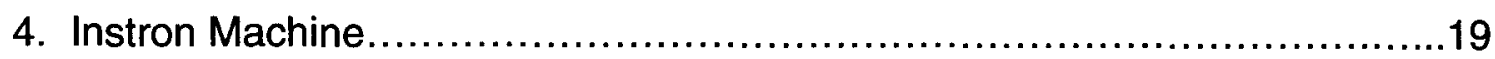

5. Instron Machine with Tooth in Place ............................................20

6. Boxplot of Varying Curing Times.........................................24

7. Boxplot for Varying Curing Distances for 5 second cure times................27

8. Boxplot for Varying Curing Distances for 10 second cure time..................28 


\section{CHAPTER I}

\section{INTRODUCTION}

Light cured bonding agents were introduced to orthodontics for bonding brackets in the 1970's. Prior to this, brackets were banded to teeth, as well as using chemically cured adhesives to bond brackets to enamel. Light cured bonding agents in orthodontics have been greatly influenced by materials used in restorative dentistry. Preparing the enamel surface by etching with acid was described early on as something that can improve the bond strength between enamel and the bonding agent. Buonocore demonstrated in 1955 that pretreatment of the enamel with $85 \%$ phosphoric acid achieved improved adhesion (Buonocore, 1955).

There are many advantages to Direct bonding as outlined by Reynolds. Some of the more obvious ones are improved esthetics and the reduced discomfort to patients. Also, the use of separators is eliminated with direct bonding. Proper oral hygiene is also easier for the patient due to the use of less bulkier appliances. As a result of this, there is less soft tissue irritation and a decreased risk of decalcification around orthodontic appliances. Furthermore, detection and treatment of caries is improved. There is also no need to close band spaces with direct bonding of orthodontic brackets. (Reynolds, 1975) 
Although there are many advantages to direct bonding, there are a few disadvantages as well. Adhesives that achieve the adequate bond strengths are often difficult to remove upon debonding. Also, the surface area available for bonding is greatly reduced in orthodontic appliances that are used for direct bonding. In other words, the surface area of a bracket pad is considerably less than the surface area of a band for adhering to the tooth surface. Furthermore, direct bonding does not provide any protection of the interproximal surfaces of teeth that bands can offer and this can be important during treatment (such as during the use of uprighting springs in Stage III Begg procedures which can make interproximal cleaning more difficult). (Reynolds, 1975)

One of the most important components of bonding is the tooth surface itself. Retief states that to achieve strong adhesion between two surfaces, they must contact at the atomic level (Retief, 1973). He goes on to state that if one of the surfaces is irregular, the other surface must be in liquid form in order to obtain the surface contact necessary for adhesion. A liquid adhesive on the surface of a tooth will create a contact angle between the surface of the tooth and the surface of the liquid. The ideal adhesive will have a contact angle as close as possible to $0^{\circ}$, which is also known as complete wettability (Retief, 1973). As previously mentioned, Buonocore was the first to suggest pre-treating enamel with acid. He suggested treating enamel with $85 \%$ phosphoric acid for 30 seconds to alter the tooth surface to allow acrylic to adhere. He proposed that the reason that acid etching produced stronger bond strengths was because it increases the surface area of enamel (Buonocore, 1955). In a study in 1971, the 
contact angle between water and tooth surface was found to be $50^{\circ}$; however, when the tooth surface was etched with $85 \%$ phosphoric acid for 30 seconds that contact angle was $0^{\circ}$. They go on to state that acid etching causes the enamel surface to change from a low energy hydrophobic to a high energy hydrophilic surface which has increased surface tension and wettability (Newman and Facq, 1971).

In addition to the surface of the tooth being bonded to, the adhesive used to bond brackets to teeth is crucial in achieving clinically acceptable bond strengths. There are 3 major groups of resins that have been used in orthodontics to bond brackets to enamel: chemical cured resins, ultraviolet cured resins, and visible light cured resins. (Pollack, 1982)

Chemically cured resins are typically composed of an amine and a peroxide catalyst (Pollack, 1982). The reaction between the amine (such as $\mathrm{N}$, $\mathrm{N}$-dihydroxyethyl-p-toludine) and the peroxide catalyst (such as benzoyl peroxide) will form free radicals and is what will initiate the hardening reaction. Typically a powder and liquid are mixed together in equal amounts to initiate the polymerization reaction. Once the polymerization reaction has been initiated, the practitioner will usually have approximately two to three minutes of working time. Two to three minutes of working time can be hindering to the practitioner, not allowing enough time to manipulate the bracket and accurately position it on the tooth surface (Wilson, 1988). Although working time is two to three minutes the polymerization reaction time continues long after the setting time is reached, in fact it can take well in excess of 24 hours (Craig, 1981). In addition to this, there 
are some other disadvantages to chemically cured composites. The mixing of the powder and liquid to form a paste introduces air into the resin. This can lead to diminished physical properties of the resin and the increased porosity can lead to surface staining. Uneven consistencies of the powder and liquid when mixed by hand will also add a potential source for weakening the bond strength, as indicated by Wilson.

Although not too commonly used anymore, another type of resin used is the ultraviolet cured composite. These composites utilize Ultraviolet radiation to initiate polymerization of the composite. Typically, these resins are cured with lights producing radiation optimized at around $365-367 \mathrm{~nm}$. Polymerization is initiated when ultraviolet radiation causes the release of free radicals by photo splitting benzoin methyl ether (Pollack, 1982). There are several advantages to ultraviolet cured resins when compared to chemically cured resins. For example, there is almost unlimited working time with UV cured resins; they only begin to set upon 20-40 second exposure with the curing unit. Also, there is no air incorporated into the paste unlike what happens in chemically cured resins. In contrast, the disadvantages of UV cured composites include poor penetration of the UV radiation through tooth structure, which can lead to several problems due to only the outer surface of the resin curing, such as discoloration, bond failure or even an unfavorable reaction between the uncured resin and the dental pulp. Furthermore, potential health hazards to the patient and dentist have been outlined by Birdsell (Birdsell and Bannon, 1977). Their findings showed that 
ultraviolet radiation can cause skin cancer, damage to the lens of the eye, or mutagenic effects.

Light cured composite resins, on the other hand, are made up of a ketone and an amine that function as initiators (Bassiouny, 1978). The ketone that is commonly found in most composite resin adhesives is camphoroquinone, which is sensitive to blue light at the wavelength of $470 \mathrm{~nm}$ (Park, Chae, Rawis, 1999). This is a single paste system and has several benefits over the ultraviolet cured composite resins. Ruyter showed that visible light has an improved depth of cure as compared to ultraviolet light (Ruyter, 1982). Curing with visible light through enamel is also more effective with visible light than with ultraviolet light (Swartz and Phillips, 1983). Many of the weaknesses of visible light cured composite resins are similar to those of ultraviolet light. Although better than ultraviolet light, light cured resin also has a limit to its depth of cure. According to Wilson, incomplete polymerization of composite can be found $2-3 \mathrm{~mm}$ beneath the surface (Wilson, 1988). Forsten showed that doubling the curing time only increased the depth of cure by approximately one third, making it 3-4 $\mathrm{mm}$ beneath the composite surface. Whereas curing through tooth substance reduced the depth of cure by at least one third, making it $1-2 \mathrm{~mm}$ beneath the composite surface (Forsten, 1984).

Wang and Meng showed that brackets bonded with the light cured composite resin, Transbond, had stronger bond strengths than brackets bonded with a self cured resin, called Concise, at times of 40 and 60 seconds of cure. In this study, they also concluded that visible light has the "capability to diffuse and 
to cure the visible light-activated orthodontic composite resin under solid metal brackets" (Wang and Meng, 1992).

The most popular method for curing throughout most of the history of light activated resins has been with halogen (QTH) curing lights. These curing lights consist of a white halogen bulb that encases iodine or bromide gas with a tungsten filament. Light is generated as the tungsten filament is heated electrically to temperatures as high as several thousands of degrees Celsius. As the tungsten filament glows, it produces light that passes through a "blue filter" (Meyer et al., 2002). This filter allows the passage of light with a wavelength range of $455-492 \mathrm{~nm}$ with the peak intensity of approximately $475 \mathrm{~nm}$.

There are some problems that are inherently found in Halogen curing lights. Due to the fact that such high temperatures are required for the tungsten filament to glow, most of the energy used produces heat radiation, which is in the infrared range of the electromagnetic spectrum. As a result, halogen curing lights are not very energy efficient, as only about $1 \%$ of the energy emitted is the light utilized for curing (Althoff and Hartung, 2000). Typically, the halogen bulb only has an effective life of approximately one hundred hours of curing time (Rueggeberg et al., 1996). The high temperatures reached by the bulb also takes its toll on the filter and reflector which can degrade over time. The halogen unit's curing effectiveness is reduced over time as a result (Barghi, 1994).

Light emitting diode (LED) curing lights have more recently gained popularity as the light source to cure composite resins. Some of the advantages 
that LED lights have over the halogen lights, as described by Stahl, Ashworth et al., are a lack of undesirable infrared and ultraviolet radiation; no degradation of the bulb, filter, and photoconductive fibers over time, along with a longer effective lifetime (Stahl, Asworth, et al. 2000). LED's use junctions of semi-conductors to produce light via electroluminescence rather than a tungsten filament. The semiconductors are constructed of gallium nitride which produces light in the blue region of the visible light spectrum (Haitz et al., 1995). Due to the fact that output of gallium nitride is at the wavelength of $400-500 \mathrm{~nm}$, a filter is not required as are with the halogen lights. Another major advantage of LED curing units is that they have a life of several thousand hours of curing time and the light output does not degrade over that period of time. Hence it can be portable very efficiently and without any loss of quality (Stahl, Asworth et al., 2000).

In an in vivo study, Koupis, Eliades et al., showed that bond failure rates between LED cured and halogen cured brackets were similar. They concluded that LED lights were an advantageous alternative due to a reduced chair time bonding procedure, without significantly affecting bond failure rate when compared to halogen curing units (Koupis, Eliades et al., 2008). In another study, the level of hardness and the degree of conversion of orthodontic resin was looked at comparing samples cured with Halogen curing lights and LED curing units. They did not find any statistical difference in hardness or degree of conversion in samples that were cured with Halogen light units cured for 10 seconds and those with the LED units cured for 5 seconds (Cerveira et al., 
2010). They concluded that only half of the time is required for curing with LED units to achieve similar resin properties.

Most recently, laser technology has started to gain wide acceptance in the use of clinical dentistry. The properties of lasers can be adapted so that lasers can be useful in restorative dentistry, pediatric dentistry, orthodontics, periodontics, and even endodontics. To understand how different types of lasers can be used in clinical dentistry, and in particular to cure resin, one must understand some basic background in how a laser works.

LASER is an acronym for Light Amplification by the Stimulated Emission of Radiation. An atom in its natural state will have all of its electrons orbiting the nucleus in the lowest energy orbitals, known as the ground state. An atom can enter its excited state, which is basically when an electron jumps up to a higher energy level after being excited by an external energy source. When the electron drops back down into its ground state, energy is emitted in the form of a photon (Harris and Pick, 1995). This photon emission is known as spontaneous emission and the type of atom being excited is what determines the characteristics of the photon.

This aforementioned stimulated emission of radiation, in other words the laser beam, possesses several features that distinguish it from traditional light sources. As Harris and Pick describe, this laser beam is monochromatic (a single wavelength), collimated (very low divergence), intense and coherent (photons in phase). Based on this information, an active medium is required to 
produce a laser beam. This active medium is a collection of atoms and is contained in either a glass or a ceramic tube. When energy is applied to this collection of atoms, electrons are excited, stimulating the emission of photons. Mirrors are placed at both ends of the tube allowing the photons to be passed back and forth through the medium and further exciting more electrons. Some of the photons are allowed to pass through an opening in one of the mirrors to form the beam (Nelson and Berns, 1988).

There are various types of mediums that can be used for lasers that are used in clinical dentistry. The mediums found in lasers that are typically used in dentistry are carbon dioxide $\left(\mathrm{CO}_{2}\right)$, erbium $(\mathrm{Er})$, Neodymium $(\mathrm{Nd})$, a combination of materials (such as Yttrium, aluminum, garnet [YAG], and Yttrium, scandium, gallium, garnet [YSSG]), Argon, diode, and excimer types (Stabholz et al., 2003). Each type of medium or combination of mediums will produce a beam of a specific wavelength. The $\mathrm{CO}_{2}(1060 \mathrm{~nm})$, Er:YAG (2940nm), Cr:YSGG (2790nm), and Nd:YAG (1060nm) all produce laser beams in the infrared region of the electromagnetic spectrum (Sulewski, 2000).

Lasers have actually been used for polymerization of composite resins in the recent past. For example, in the late 1980's and early 1990's Argon lasers were being used to cure composites. The wavelengths that are produced by this laser are in the blue region of the spectrum, of about $457.9 \mathrm{~nm}$ to $514.5 \mathrm{~nm}$ (Cobb and Vargas, 1996), which is sufficient enough to activate the ketone initiator, camphoroquinone. In a study done by Kelsey, Blankenau et al., they compared the physical properties of restorative resins polymerized by an Argon 
Laser and a conventional light source (Halogen curing light). They found increases in the tensile, flexural, diametral tensile and compressive strengths of composite cured by an Argon laser, although the only one that was statistically significant was the diametral tensile strength difference (Kelsey, Blankenau et al., 1989a). These results were achieved with one quarter of the curing time that was required with conventional visible light. In another study by Blankenau and Powell et al., they found a significantly greater degree of microfilled resin polymerization was achieved following Argon Laser curing compared to Halogen light curing (Blankenau, Powell et al., 1991). Another advantage that was found with the Argon laser was reduced polymerization shrinkage of composite material, which was attributed to a homogenous penetration of the beam (Frentzen and Koort, 1990).

In addition to the physical properties and characteristics of the composite itself, the bond strengths that form between the composite and the enamel or dentin are of critical importance. In a study performed by the same group looking at the physical properties of resin polymerized by Argon lasers, they found that restorative resin was polymerized by an Argon laser in 75 percent less exposure time than visible light activation, resulted in comparable enamel shear strengths and even higher dentin bond strengths (Powell, Kelsey, Blankenau et al., 1989b).

In studies specific to orthodontic resin and adhesives, Talbot et al found that the Argon Laser can polymerize orthodontic resin four times faster than halogen light curing with similar or higher bracket bond strengths (Talbot et al., 2000). Furthermore, a lower frequency of enamel fractures was found at 
debonding in brackets polymerized with Argon Laser as compared to conventional light cured brackets (Lalani, Foley, et al., 2000). Damage to pulpal tissue during curing as a result of generating excessive heat is also of concern. It has been found that Argon Laser curing should not pose a serious threat to pulpal tissue if used at recommended energies (Cobb et al., 2000). Temperature changes of the pulpal tissue at recommended curing times with the Argon laser were found to only increase by $3^{\circ} \mathrm{F}$ or less which was found to be significantly less than those of conventional curing lights (Powell, Anderson, Blankenau, 1999). In vivo, bond strengths for argon laser curing was found to be comparable to those of a conventional curing light (Halogen curing light) and with no increase in enamel surface fractures (Hildebrand et al., 2007).

The effects of lasers on enamel have been studied for some time, proving that lasers also play a role in caries susceptibility. In 1965, Sognnaes and Stern found that lasing human enamel gives it some resistance to demineralization due to acid attack (Sognnaes and Stern, 1965). Microradiography revealed that irradiation with the Argon laser reduces the amount of demineralization of enamel by $30-50 \%$ (Duncan et al., 1993). Although the exact mechanism of how this works is not known, it has been suggested that the creation of microspaces within the enamel is the likely mechanism for caries resistance (Noel, Rebellato, Sheats, 2003). These microspaces trap ions (Calcium and Phosphate) that are released during demineralization, and these sites act as areas for "reprecipitation within the enamel structure." If the microspaces are not present, as in non-lased enamel, the ions are lost to the oral environment. This mechanism goes along 
with the conclusion that lased enamel has a greater attraction to calcium, phosphate and fluoride ions (Fox et al., 1992). Noel et al found that brackets that have been cured for ten seconds with the Argon Laser resulted in $22 \%$ less demineralization depth when compared to the samples cured with visible light.

In addition to curing time, the distance of the curing tip to the composite surface is also a critical component in achieving high bond strengths. Rode, Kawano et al. (2007) showed that greater tip distances produce a decrease in microhardness and degree of conversion values. The curing tip at 5-10 $\mathrm{mm}$ from the composite surface over a curing time of 20 seconds showed significantly lower bond strengths as compared with those cured at smaller distances (Bayne, Heymann et al., 1994). Rueggeberg showed that at a less than $4 \mathrm{~mm}$ tip to resin distance, polymerization was still primarily dependent on duration of exposure, although intensity played a role (Rueggeberg, Jordan, 1993). When comparing LED curing units with Halogen curing units, it was found that LED's did not provide a clinically sufficient cure when placed $10 \mathrm{~mm}$ from the resin surface, and the LED's intensity went down faster than the Halogen light (Meyer et al., 2002). It is not always possible to have the light source $5 \mathrm{~mm}$ or less from the adhesive, even though many manufacturers will use this distance assuming the ideal. As a result, it has been suggested to increase the curing time from what the manufacturer recommends (Bayne, Heymann et al.1994).

Argon Lasers have been studied extensively and have been shown to have many advantages, however they have not gained widespread use clinically due to their construction and cost (Knezevic et al., 2007). Diode-pumped solid 
state lasers are an alternative that appear to be promising because of their compactness, price and efficiency of these lasers over others (Jang et al., 2009). These lasers are constructed by pumping a solid medium with a laser diode. Blue light diode lasers are made from an indium gallium nitride medium and have a wavelength output of $473 \mathrm{~nm}$ which is very near the peak absorption of camphoroquinone at $470 \mathrm{~nm}$. Knezevic et al. found a higher degree of conversion for the polymerization of composite samples with the LED over the Blue diode laser, however the difference was not statistically significant. Jang et al. found that the Blue Light Diode Laser effectively polymerizes dental nanocomposite resins to a similar extent as that of Halogen, LED, and Xenon lamp-based plasma arc curing units. Due to these findings and the benefits that the Argon laser can potentially achieve, it is speculated that this blue light diode laser could realize similar composite characteristics, bond strengths and polymerization rates.

Due to the fact that the blue light diode lasers produce a beam that is collimated and as a result has a high energy per millimeter at greater distances relative to other curing sources, it is worthwhile to test it to see if greater tip distance of the blue light diode laser can produce comparable bond strengths. 


\section{CHAPTER II}

\section{METHODS AND MATERIALS}

Specific Aims: One of the aims of this study will be to test the bond strength of orthodontic brackets bonded to enamel with varying cure times using a blue light diode laser and a LED curing light. The cure times that will be used are 3,5, and 10 seconds. The hypothesis for this aim is that similar bond strengths will be achieved with the blue light diode laser in one half of the time needed for LED light cured brackets.

The second aim of this study is to test the optimal distance for the curing tip to be from the composite resin/bracket-enamel interface. Bond strengths will be measured on brackets bonded to enamel with varying distances $-3 \mathrm{~mm}, 6 \mathrm{~mm}$, and $10 \mathrm{~mm}$ - cured with blue light diode laser and the LED curing light for 5 and 10 seconds. The hypothesis for this aim is that the bond strengths achieved with the blue diode laser will be the same at distances of $10 \mathrm{~mm}$ as that of the closer distances.

\section{Methods and Materials}

This is a prospective experimental laboratory study. Bond strengths of light activated composite resin used to bond orthodontic brackets to enamel of teeth were measured. These composite resins were polymerized using a blue 
light diode laser as well as a Light Emitting Diode (LED) curing unit for different lengths of time, as well as at varying distances of the curing tip to the composite resin.

To test the bond strengths of polymerized composites at differing time intervals, two hundred and ten extracted virgin teeth were collected. These teeth were obtained from the oral surgery department at the University Of Louisville School Of Dentistry. The criteria for selection of teeth were as follows: did not possess any enamel defects on the buccal surface, did not have any carious lesions on the buccal surface, no fracture lines, did not have any restorations on the buccal surface, and that the teeth were not fractured or damaged from the forceps during extraction. The teeth were disinfected using a Sodium Hypochlorite:Water solution in the ratio of $1: 10$. The teeth were then thoroughly rinsed with water for 5 minutes and stored in a $0.1 \%$ Thymol Solution (weight/volume).

\section{Bond Strengths of Brackets Cured with Varying Time}

Ninety teeth were divided into three groups according to the curing times of 3,5 and 10 seconds. Furthermore within the groups, each tooth was cured by either the blue light diode laser or the LED curing unit, which was used as the control group. Each of the teeth were etched with Ultra-Etch 35\% phosphoric acid etchant (Ultradent Products, Inc., South Jordan UT ) for 20 seconds, thoroughly rinsed with water for 15 seconds and then dried with oil-free air for another 10 seconds. The tooth was then coated with a thin layer of Assure 
bonding resin (Reliance Orthodontic Products, Inc., Itasca IL) using a brush tip applicator and then thinned out once again with oil-free air for 5 seconds.

The brackets that were bonded to the teeth were stainless steel 3M Unitek Victory Series brackets (3M Unitek Inc., St. Paul MN) with a .022 inch slot size. They are APC brackets, which are pre-coated with resin that is placed on the bracket pad by the manufacturer according to their specifications of $8.5 \mathrm{mg}+/-$ $1.5 \mathrm{mg}$ of Transbond XT orthodontic. Each of the brackets were placed in the center of the facial/buccal surface by one operator to eliminate the operator as a variable. A Correx gauge (Correx Co., Bern Switzerland) was used to apply force to seat the bracket on the tooth so that every bracket was placed with the same amount of force on each tooth. A force of 250 grams was applied to seat the brackets. Any flash or excess composite was removed by the operator with the use of a dental scaler.

As stated earlier, half of the teeth in each of the three groups were cured using a fully charged 3M Unitek Ortholux LED curing unit (3M Unitek Inc., St. Paul MN). The light intensity of the curing light was measured at $820 \mathrm{~mW} / \mathrm{cm}^{2}$. According to the manufacturer, each bracket needs to be cured for 10 seconds with half of the cure time from the mesial and the other half from the distal at a distance of $2-5 \mathrm{~mm}$ from the curing tip to the adhesive. The manufacturer recommendation of half the cure time from the mesial and half the cure time from the distal was followed, with the alteration of curing times varying for 3,5 and 10 seconds depending on which of the three groups were being cured. The distance of the curing tip to the bracket-resin-enamel interface was $3 \mathrm{~mm}$ and 
was held constant for every group. After the brackets were cured, they were stored in a dark container to prevent any additional curing from exposure to any other light source. The other half of the teeth were cured with an Aquarius blue light diode laser (Laser Glow Technologies Inc., Toronto, ON Canada) following the same manufacturer's recommendations for curing technique and also stored in a dark container. According to the manufacturer of the Aquarius laser, the wavelength output is $473 \mathrm{~nm}$ with a power stability of $<10 \% \mathrm{RMS} / 4 \mathrm{hrs}$ and $0-100$ $\mathrm{mW}$ variable intensity, with a laser beam diameter of $3 \mathrm{~mm}$ (Figure 1). The intensity of the laser was measured to be $43 \mathrm{~mW}$ for a $3 \mathrm{~mm}$ beam diameter for this study. The resulting light intensity was approximately $610 \mathrm{~mW} / \mathrm{cm}^{2}$.

\section{Figure 1: Aquarius Blue Light Diode Laser}

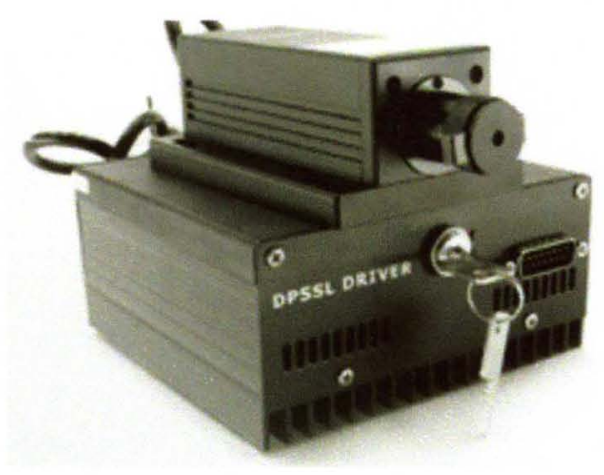

The teeth were then mounted in a mounting jig where the base allows the tooth to be adjusted in three planes of space (Figure 2). The teeth were then positioned so that the long axis of the tooth was perpendicular to the base and the crosshead of the Instron machine using a dental surveyor (Figure 3). 
Figure 2: Dental Surveyor to Level Bracket Wings

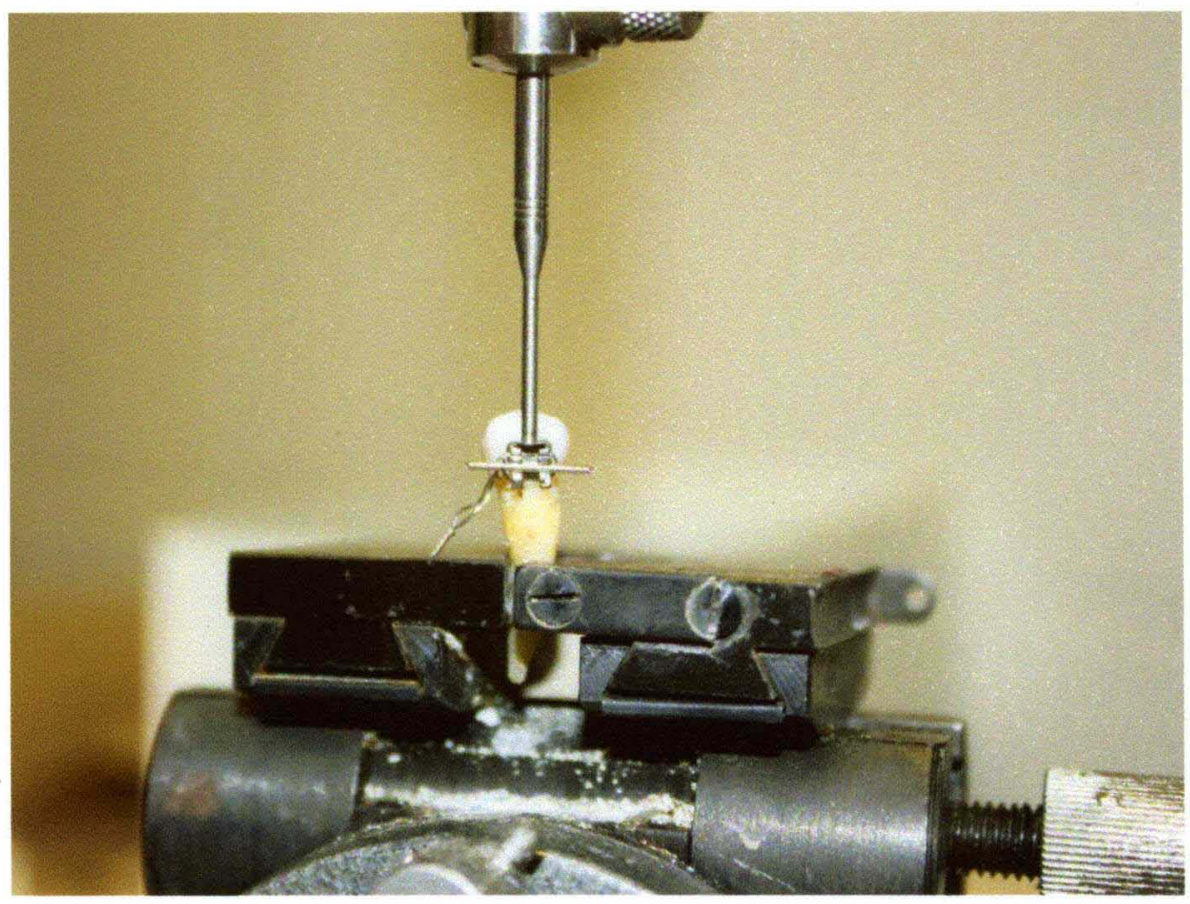

Figure 3: Dental Surveyor to Parallel Long axis of tooth

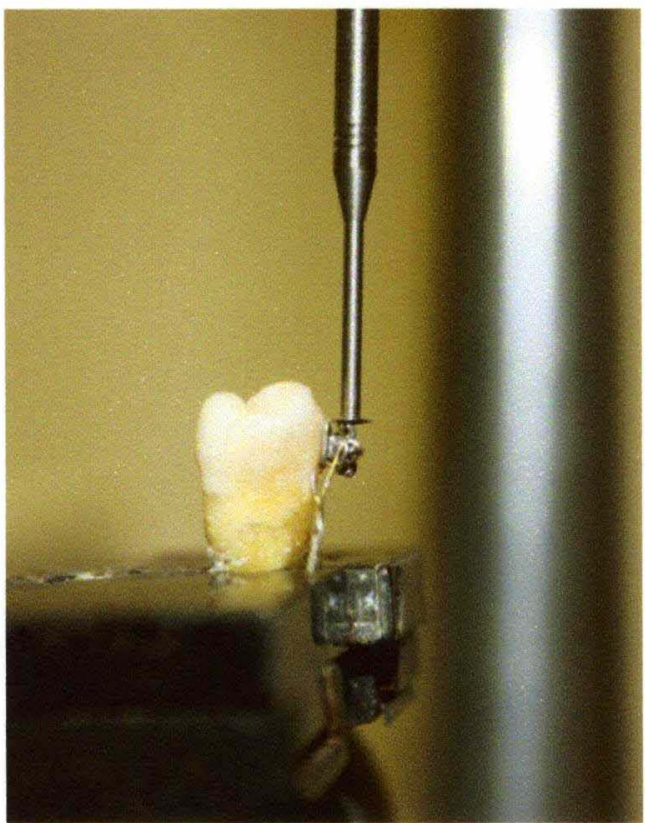


The bond strength of light activated resin adhesive bonding with the bracket to tooth enamel was tested with an Instron machine Model \#1362 (Instron Inc., Canton, MA). (Figure 4)

Figure 4: Instron Machine

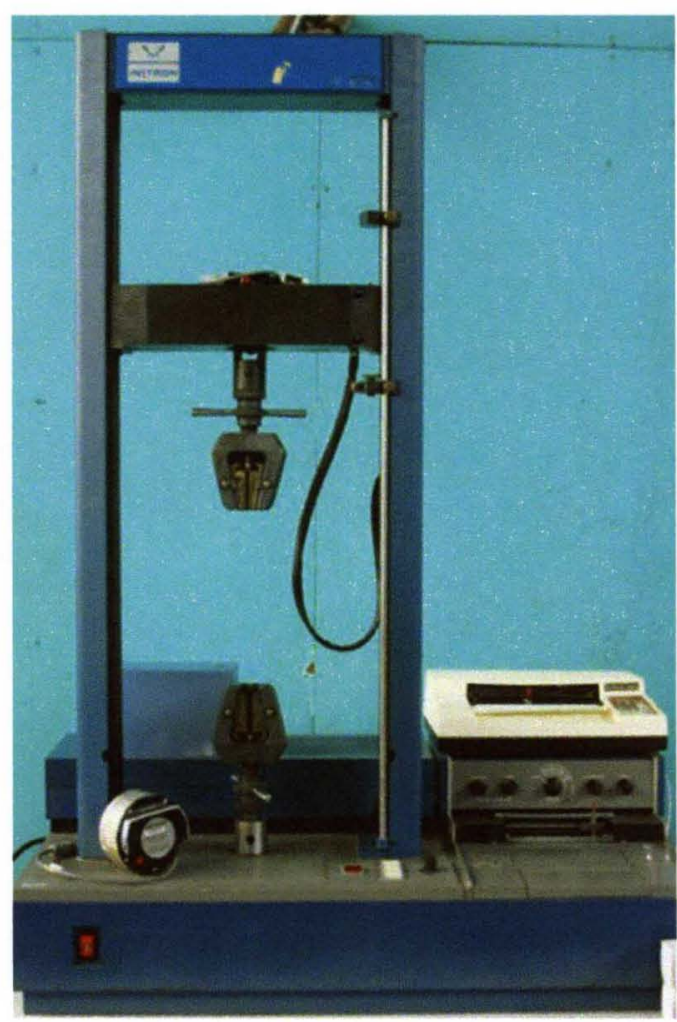


Figure 5: Instron Machine with Tooth in Place

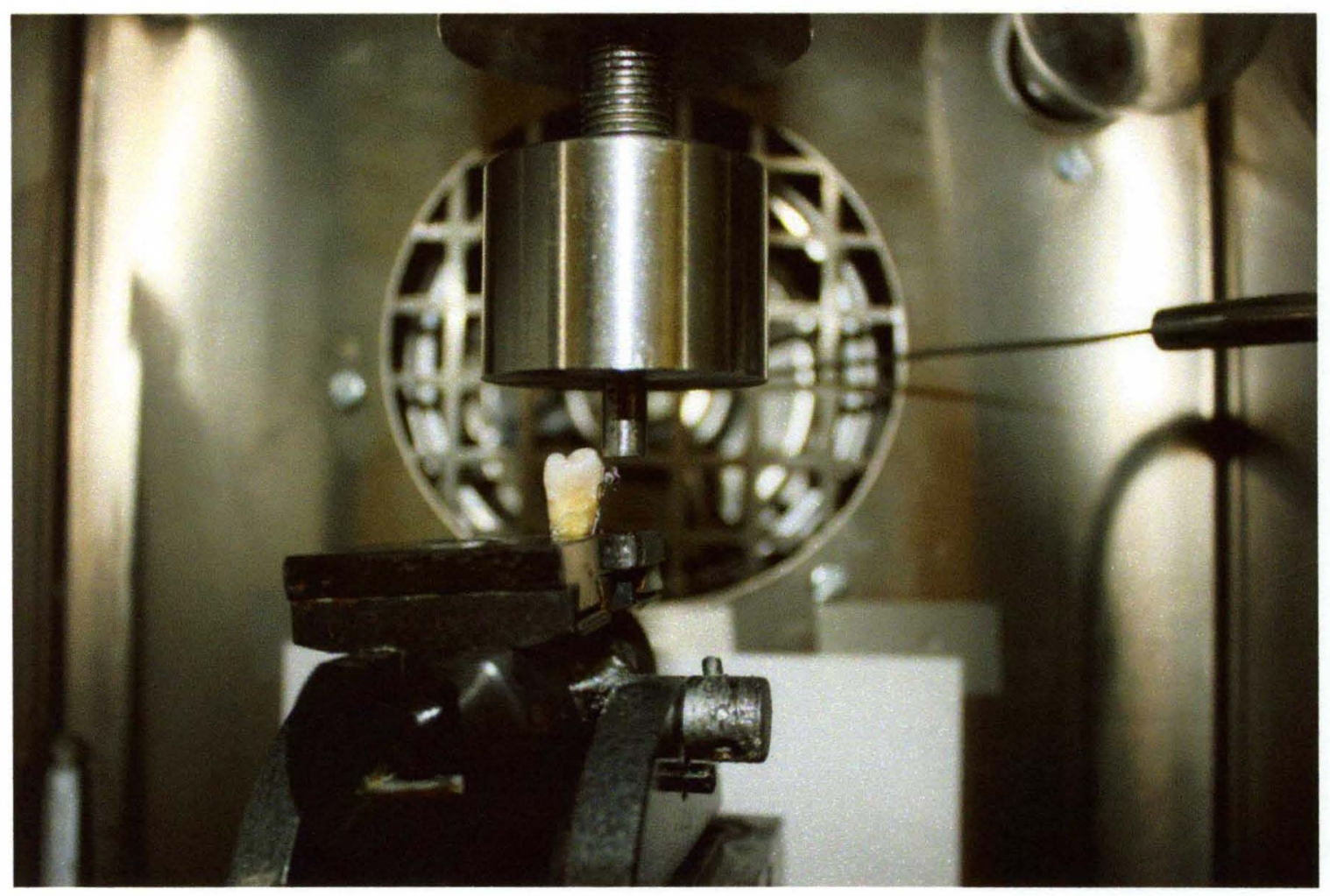

This will test the bond strength by placing a shear-peel force in a direction parallel to the long axis of the tooth. The force was applied with a crosshead with a speed of $0.4 \mathrm{~mm} / \mathrm{min}$ using a decade reducer. The Instron machine measures the shear-peel force in Newtons $(\mathrm{N})$ and was then converted to MegaPascals (MPa) by dividing the force in Newtons by area of the bracket pad. According to $3 \mathrm{M}$ Unitek the area of the bracket pad is $10.23 \mathrm{~mm}^{2}$ for their premolar brackets.

Once the bond strengths were measured, each tooth was examined under 20 times magnification to see how much resin was left on the tooth after debonding and an Adhesive Remnant Index (ARI) Score was assigned to each tooth. Each tooth was scored 0-4 depending on how much resin was left on the 
buccal surface of the teeth based on guidelines set forth by Artun and Bergland (1984). Each tooth was scored as follows:

0 represents no resin left on the tooth

1 represents less than or equal to $50 \%$ of the resin left on the tooth

2 represents more than $50 \%$ of the resin left on the tooth

3 represents $100 \%$ of the resin left on the tooth

4 represents an enamel fracture occurred during debonding

\section{Bond Strengths of Brackets Cured with Varying Distance of Curing}

\section{Tip}

For the second aim of this study, one hundred and twenty extracted teeth were used. They were obtained from the Oral Surgery department at the University Of Louisville School Of Dentistry as well. The teeth were divided into three groups to be cured at varying distances of $3 \mathrm{~mm}, 6 \mathrm{~mm}$, and $10 \mathrm{~mm}$. Teeth were prepared and brackets were bonded to teeth in a similar fashion as what was described earlier. Within each of the three groups of 40 teeth each, the teeth were further subdivided into four subgroups: 10 teeth were cured for 5 seconds with the blue light diode laser, 10 teeth for 5 seconds with the LED curing unit, 10 teeth for 10 seconds with the blue light diode laser, and 10 teeth for 10 seconds with the LED curing unit with the curing tips being placed at varying distances from the bracket-enamel interface. Bond strengths of the bonded brackets and ARI scores were measured as described earlier. 


\section{Statistical Analysis}

The statistical analysis that was performed was the two way analysis of variance (ANOVA). The controls in both parts of the study are the samples cured with the LED curing light. The outcomes that are expected for the first part of the study are that similar bond strengths will be achieved in the samples cured by the Blue light diode laser in one half of the time of the samples that are cured with the LED curing units. For the second part of the study, the outcome expected is that samples cured at a greater distance with the Blue light diode laser will achieve similar bond strengths as those samples cured at shorter distances. The reason for the expected outcome is that a laser's intensity should not decrease even if the distance of the laser is increased; also a laser's beam tends to have minimal dispersion. The adhesive remnant index was evaluated with the use of the Pearson Chi-Squared Test Statistic to look for differences between groups. 


\section{CHAPTER III}

\section{RESULTS}

The following table (Table 1) summarizes the data collected from the first part of this study, measuring bond strengths in brackets cured with Laser and LED curing units at varying curing times.

Table 1: Bond Strengths with Varying Curing Times

\begin{tabular}{cccccc}
\hline $\begin{array}{c}\text { Curing } \\
\text { Light }\end{array}$ & $\begin{array}{c}\text { Curing } \\
\text { Time } \\
\text { (Seconds) }\end{array}$ & $\begin{array}{c}\text { Sample } \\
\text { Size }\end{array}$ & $\begin{array}{c}\text { Mean Bond } \\
\text { Strength } \\
\text { (MPa) }\end{array}$ & $\begin{array}{c}\text { Standard } \\
\text { Deviation }\end{array}$ & Range \\
\hline LED & 10 & 15 & 11.81 & 2.48 & $9.27-16.52$ \\
Laser & 10 & 15 & 13.21 & 2.09 & $10.41-16.76$ \\
LED & 5 & 15 & 11.96 & 2.44 & $7.01-14.77$ \\
Laser & 5 & 15 & 7.69 & 2.39 & $4.82-11.84$ \\
LED & 3 & 15 & 11.00 & 2.62 & $6.53-13.68$ \\
\hline Laser & 3 & 15 & 5.50 & 1.46 & $3.25-7.72$ \\
\hline
\end{tabular}

A boxplot shows how the data set was distributed (Figure 6) 
Figure 6: Boxplot of Varying Curing Times

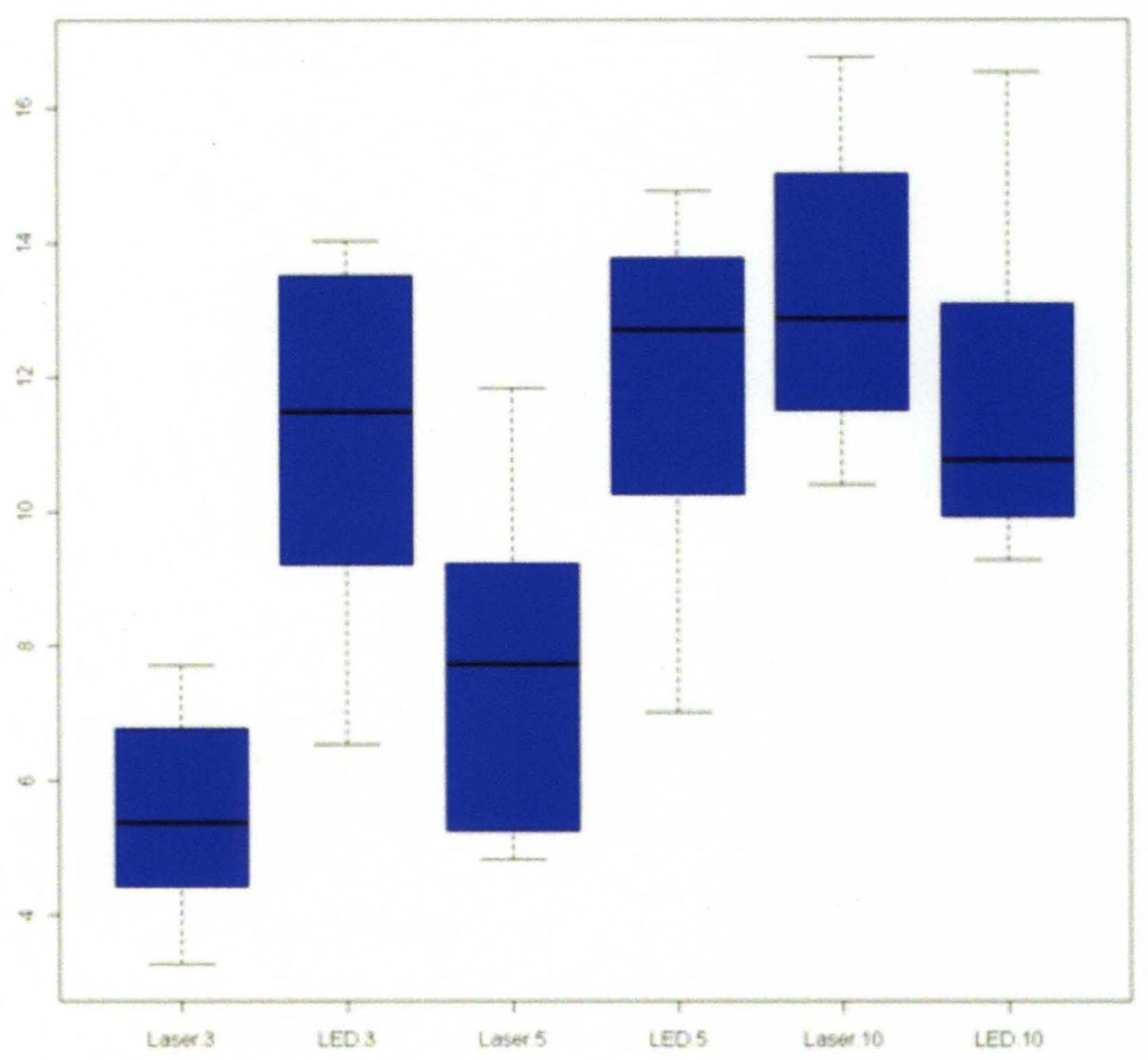

A two-way ANOVA showed a statistically significant difference between bond strengths of brackets cured for 3 and 5 seconds with the laser when compared to the LED at 10 seconds. (Table 2) 
Table 2: P-Values for Varying Curing Times

\begin{tabular}{cc}
\hline Variable Combination & P-Value \\
\hline LED 10 seconds & Reference Level \\
\hline Laser $\mathbf{1 0}$ seconds & 0.10 \\
LED 5 seconds & 0.87 \\
Laser $\mathbf{5}$ seconds & $3.57 \times 10^{-6}$ \\
LED 3 seconds & 0.33 \\
Laser 3 seconds & $3.88 \times 10^{-11}$ \\
\hline
\end{tabular}

The adhesive remnant index was calculated and shown in the following table (Table 3):

Table 3: ARI for Varying Curing Times

\begin{tabular}{ccccccc}
\hline ARI & LED 10 & LED 5 & LED 3 & Laser & Laser & Laser \\
& sec & sec & sec & 10sec & 5sec & 3sec \\
\hline $\mathbf{0}$ & $0 \%$ & $0 \%$ & $0 \%$ & $0 \%$ & $6.7 \%$ & $20 \%$ \\
$\mathbf{1}$ & $13.3 \%$ & $13.3 \%$ & $13.3 \%$ & $20 \%$ & $33.3 \%$ & $46.7 \%$ \\
$\mathbf{2}$ & $26.7 \%$ & $26.7 \%$ & $40 \%$ & $33.3 \%$ & $40 \%$ & $26.7 \%$ \\
$\mathbf{3}$ & $46.7 \%$ & $53.3 \%$ & $40 \%$ & $46.7 \%$ & $20 \%$ & $6.7 \%$ \\
$\mathbf{4}$ & $13.3 \%$ & $6.7 \%$ & $6.7 \%$ & $0 \%$ & $0 \%$ & $0 \%$ \\
\hline $\mathrm{X}^{2}=16.39, \mathrm{P}=0.174$ & & & & & \\
\hline
\end{tabular}


For the second part of this study, bond strengths were measured on brackets bonded by varying the distance from the tip of the curing unit to the bracket pad. The brackets were cured with either the blue light diode laser or the LED for 5 seconds or 10 seconds. The data collected is summarized in the following tables (Table 4 for 5 seconds curing and Table 5 for 10 seconds curing).

Table 4: Comparison of Varying Distances Cured for 5 seconds

\begin{tabular}{cccccc}
\hline $\begin{array}{c}\text { Curing } \\
\text { Light }\end{array}$ & $\begin{array}{c}\text { Curing } \\
\text { Distance } \\
(\mathrm{mm})\end{array}$ & $\begin{array}{c}\text { Sample } \\
\text { Size }\end{array}$ & $\begin{array}{c}\text { Mean } \\
\text { Bond } \\
\text { Strength } \\
(\mathrm{MPa})\end{array}$ & $\begin{array}{c}\text { Standard } \\
\text { Deviation }\end{array}$ & Range \\
\hline LED & 3 & 10 & 12.10 & 3.09 & $7.51-17.93$ \\
LED & 6 & 10 & 8.37 & 1.26 & $6.32-10.51$ \\
LED & 10 & 10 & 4.47 & 1.96 & $2.10-5.71$ \\
Laser & 3 & 10 & 6.71 & 1.39 & $4.72-8.12$ \\
\hline Laser & 6 & 10 & 6.43 & 2.64 & $4.20-13.25$ \\
\hline Laser & 10 & 10 & 4.79 & 2.65 & $2.84-11.80$ \\
\hline
\end{tabular}


Table 5: Comparison of Varying Distances Cured for 10 seconds

\begin{tabular}{cccccc}
\hline $\begin{array}{c}\text { Curing } \\
\text { Light }\end{array}$ & $\begin{array}{c}\text { Curing } \\
\text { Distance } \\
(\mathrm{mm})\end{array}$ & $\begin{array}{c}\text { Sample } \\
\text { Size }\end{array}$ & $\begin{array}{c}\text { Mean } \\
\text { Bond } \\
\text { Strength } \\
(\mathrm{MPa})\end{array}$ & $\begin{array}{c}\text { Standard } \\
\text { Deviation }\end{array}$ & Range \\
\hline LED & 3 & 10 & 11.83 & 2.68 & $8.11-16.51$ \\
LED & 6 & 10 & 8.82 & 1.65 & $6.12-12.10$ \\
LED & 10 & 10 & 6.64 & 2.08 & $4.29-11.39$ \\
Laser & 3 & 10 & 13.09 & 3.20 & $8.32-18.83$ \\
\hline Laser & 6 & 10 & 11.17 & 2.21 & $6.51-14.28$ \\
Laser & 10 & 10 & 10.23 & 2.36 & $8.30-16.13$ \\
\hline
\end{tabular}

A box plot shows how the data was distributed (Figure 7 and 8)

Figure 7: Boxplot for Varying Curing Distances for 5 second cure times

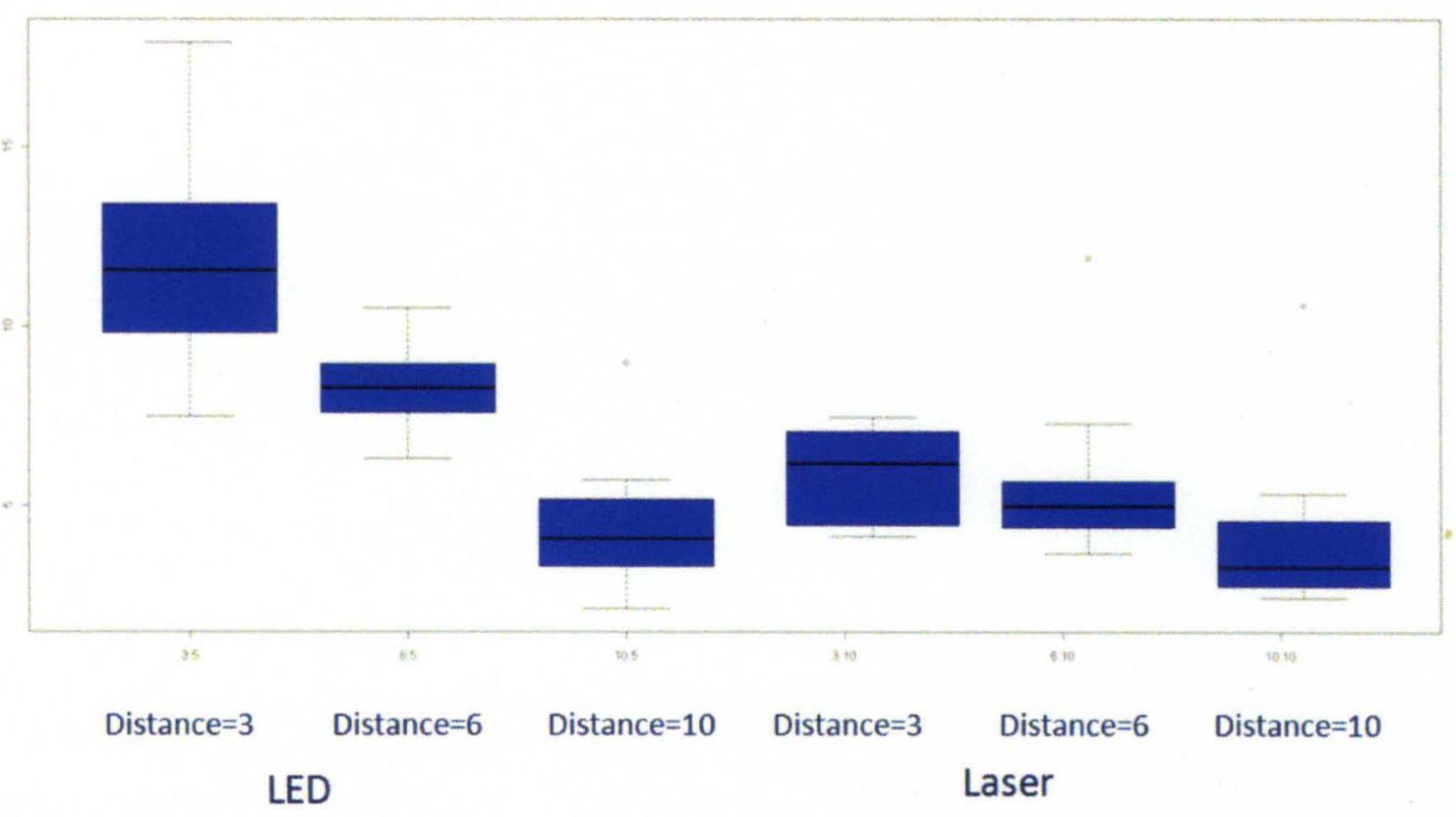


Figure 8: Boxplot for Varying Curing Distances for 10 second cure times

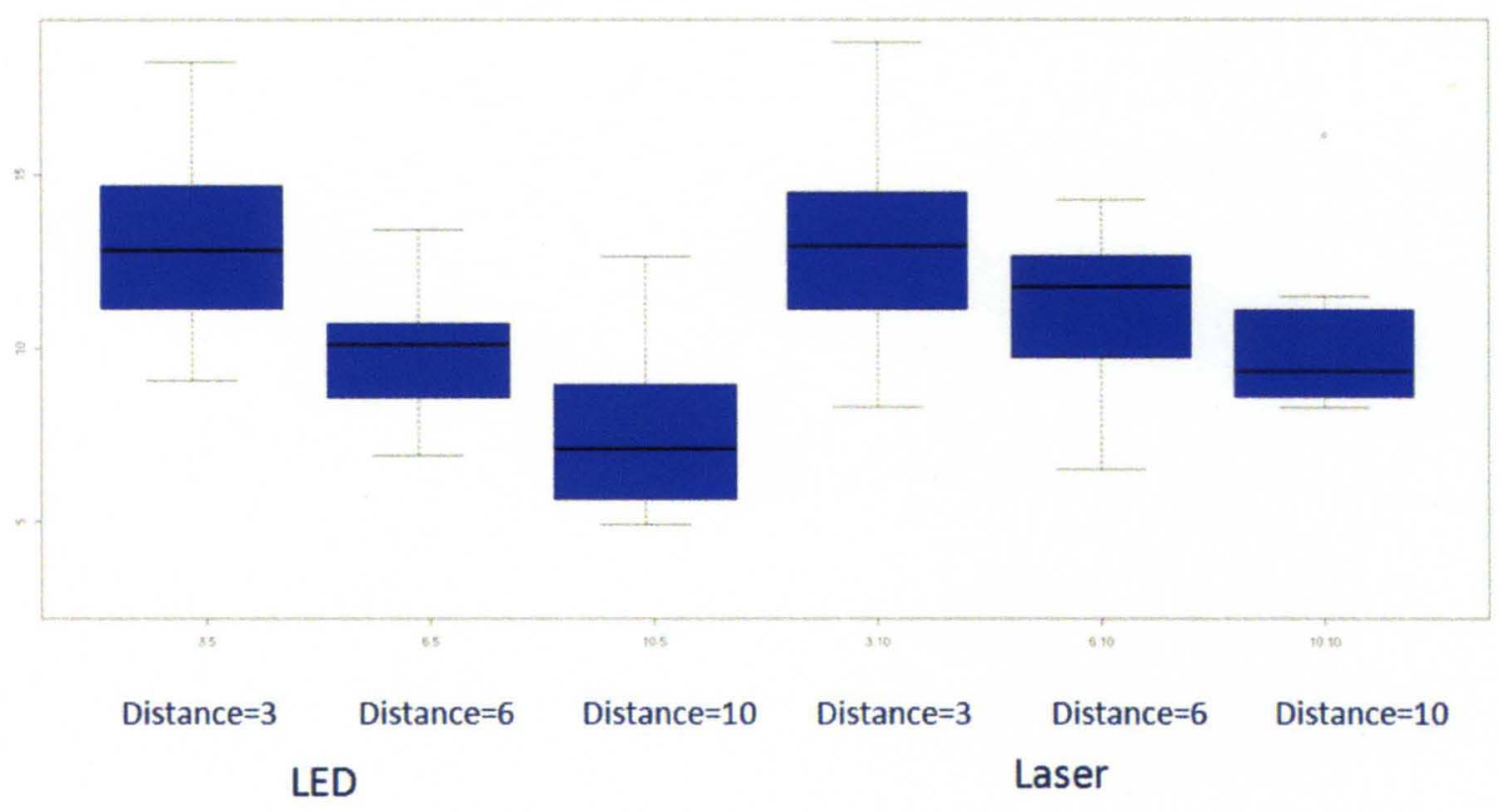

A regression analysis was performed on this data set. The results were statistically significant for the LED curing light for both the 5 and 10 second curing times ( $p$ value of $<0.0001$ for both the 5 and 10 second curing time data sets). The results for the laser curing unit were not statistically significant ( $p$ value of 0.06 for the 5 second curing times and 0.22 for the 10 second cured brackets).

The estimated effect of cure distance was calculated (Table 6).

Table 6: Effect of Cure Distance

\begin{tabular}{lcccc} 
& \multicolumn{2}{c}{5 second curing } & \multicolumn{2}{c}{$\mathbf{1 0}$ second curing } \\
\hline & LED & Laser & LED & Laser \\
\hline $\begin{array}{c}\text { Effect of } \\
\begin{array}{c}\text { Cure } \\
\text { distance }\end{array}\end{array}$ & $\begin{array}{c}-1.08 \\
\left(-1.37^{-}-0.79\right)\end{array}$ & $(-0.58-0.01)$ & $(-1.01--0.45)$ & $(-0.74--0.06)$ \\
\hline $95 \%$ Confidence Intervals in Parentheses & & -0.40 \\
\hline
\end{tabular}


This basically indicates that for millimeter increase in curing distance, that is the amount of change that will be seen in bond strength in MegaPascals. For example, for the LED brackets cured for 5 seconds, each millimeter that was increased for curing distance resulted in a decrease in bond strength by 1.08 MPa.

The adhesive remnant index was calculated and shown in the following tables (Table 7 and 8 ):

Table 7: ARI for Varying Curing Distance cured for $\mathbf{5}$ seconds

\begin{tabular}{ccccccc}
\hline ARI & LED 3 & LED 6 & LED 10 & Laser & Laser & Laser \\
& $\mathbf{m m}$ & $\mathbf{m m}$ & $\mathbf{m m}$ & $\mathbf{3 m m}$ & $\mathbf{6 m m}$ & $\mathbf{1 0 \mathbf { m m }}$ \\
\hline $\mathbf{0}$ & $0 \%$ & $10 \%$ & $20 \%$ & $0 \%$ & $0 \%$ & $0 \%$ \\
\hline $\mathbf{1}$ & $20 \%$ & $70 \%$ & $50 \%$ & $40 \%$ & $30 \%$ & $0 \%$ \\
\hline $\mathbf{2}$ & $70 \%$ & $20 \%$ & $20 \%$ & $50 \%$ & $50 \%$ & $50 \%$ \\
\hline $\mathbf{4}$ & $10 \%$ & $0 \%$ & $0 \%$ & $0 \%$ & $20 \%$ & $50 \%$ \\
\hline $\mathrm{X}^{2}=23.51, \mathrm{P}=0.024$ & & $10 \%$ & $10 \%$ & $0 \%$ & $0 \%$ \\
\hline
\end{tabular}


Table 8: ARI for Varying Curing Distance cured for 10 seconds

\begin{tabular}{ccccccc}
\hline ARI & LED 3 & LED 6 & LED 10 & Laser & Laser & Laser \\
& $\mathbf{m m}$ & $\mathbf{m m}$ & $\mathbf{m m}$ & $\mathbf{3 m m}$ & $\mathbf{6 m m}$ & $\mathbf{1 0 m m}$ \\
\hline $\mathbf{0}$ & $0 \%$ & $10 \%$ & $10 \%$ & $0 \%$ & $0 \%$ & $0 \%$ \\
$\mathbf{1}$ & $10 \%$ & $40 \%$ & $50 \%$ & $0 \%$ & $10 \%$ & $10 \%$ \\
$\mathbf{2}$ & $40 \%$ & $40 \%$ & $40 \%$ & $20 \%$ & $40 \%$ & $50 \%$ \\
\hline $\mathbf{4}$ & $40 \%$ & $0 \%$ & $0 \%$ & $80 \%$ & $50 \%$ & $40 \%$ \\
\hline $\mathrm{X}^{2}=21.72, \mathrm{P}=0.041$ & & $10 \%$ & $0 \%$ & $0 \%$ & $0 \%$ & $0 \%$ \\
\hline
\end{tabular}




\section{CHAPTER IV}

\section{DISCUSSION}

In this present study, the bond strengths that were achieved were comparable to previous studies in which similar materials and methods were used (Bishara, 2001). Reynolds has outlined that 5.9-7.8 MPa is clinically acceptable for bracket bond strength (Reynolds, 1975). The bond strengths that were measured for the control group of curing with the LED curing unit for the manufacturer recommended 10 seconds per bracket was found to be $11.81 \mathrm{MPa}$ with a standard deviation of 2.48. Retief states that clinical bond strengths at or above 13.7 MPa can have enamel fractures upon debond (Retief, 1974).

The bond strengths that were measured in this study were shear-peel bond strengths. This is comparable to most other studies that have looked at bond strength despite the incorrect terminology of shear strength. Due to the anatomy of the tooth surface, the geometry and shape of the bracket pad and bracket itself, it is impossible to apply a pure shear force to measure bond strength and therefore, the correct terminology is shear-peel bond strength.

Due to all of these variables that can affect the shear-peel bond strength, the location that the force is applied is incredibly important. Katona and Moore found that if the tensile load was accidentally placed on only one wing of a 
bracket, the stress levels nearly double in magnitude (Katona and Moore, 1994). Klocke and Kahl-Nieke found that deviations in force angulation can cause huge variations in measured bond strengths (Klocke and Kahl-Nieke, 2006). They found that a change of $15^{\circ}$ from a force parallel to the bracket base toward the enamel causes an increase of $27.9 \%$ of shear stress measurements.

Conversely, a $27.4 \%$ decrease in shear bond strength was seen when a force is applied at a $15^{\circ}$ magnitude of deviation away from the enamel. Not only were bond strengths affected, the point of bond failure was also different. More adhesive was left on teeth after debonding when the force was angulated away from the enamel.

It is because of this that each tooth was positioned very meticulously prior to being placed in the Instron machine. As shown in Figure 3, the tooth was placed in the mounting jig and was positioned using a dental surveyor to be certain that the shear-peel will be placed parallel to the long access of the tooth. Furthermore, each tooth was visually inspected to make sure that load was applied equally on both wings of the bracket and not just one. Only premolar teeth and premolar brackets were used in order to help minimize variations due to differences in bracket pad size and shape and well as the bracket itself.

A crosshead speed of $0.4 \mathrm{~mm} / \mathrm{min}$ was used in this study. There is great variation in crosshead speed used in much of the orthodontic literature. Crosshead speeds have ranged from as low as $0.1 \mathrm{~mm} / \mathrm{min}$ up to $5 \mathrm{~mm} / \mathrm{min}$. Fox et al. (1994) have recommended a $0.1 \mathrm{~mm} / \mathrm{min}$ crosshead and Eliades and Brantley (2000) have recommended $0.5 \mathrm{~mm} / \mathrm{min}$. However, these values are 
significantly slower than what may be found in vivo, in which cases debonding likely will involve a higher velocity impact. James et al. state that using a slower crosshead speed might better remove the influence of the material's strain rate sensitivity (James et al, 2003).

A statistically significant difference was found in shear-peel bond strengths in samples cured with the laser curing unit at 3 and 5 seconds versus the control of 10 second curing time with the LED curing unit. The laser yielded $5.50 \mathrm{MPa}$ and $7.69 \mathrm{MPa}$ shear-peel bond strengths at 3 and 5 seconds of cure time respectively ( $p$-value at 3 seconds was $3.88 \times 10^{-11}$ and the $p$-value for 5 seconds was $\left.3.57 \times 10^{-6}\right)$. This is in contrast to the hypothesized outcome that the laser curing unit would be able to produce similar shear-peel bond strengths with shorter curing times as the LED curing unit at 10 seconds of curing time (11.81 $\mathrm{MPa})$.

The reason for the decreased shear-peel bond strength found in this study at shorter cure times for the blue light diode laser cured samples could possibly be because of the considerably lower light intensity. The light intensity of the LED curing unit was measured at $820 \mathrm{~mW} / \mathrm{cm}^{2}$, while the light intensity for the laser was $610 \mathrm{~mW} / \mathrm{cm}^{2}$. As James et al. state, even though a narrower wavelength and collimation are beneficial, the total light energy appears to be a more important factor when determining the degree of polymerization (James et al, 2003). Another possibility for these results could be that the diameter of the beam produced by the laser was too small. The diameter of the laser beam was $3 \mathrm{~mm}$ according to the manufacturer. This could potentially lead to incomplete 
beam penetration of all areas of the adhesive. If this was the case, than some areas of the bracket-adhesive-tooth junction would show reduced polymerization and therefore yield lower bond strengths.

Interestingly, the shear-peel bond strengths achieved with the laser cured samples for 10 seconds were slightly higher than the LED cured samples for 10 seconds, which was $13.21 \mathrm{MPa}$ compared to $11.81 \mathrm{MPa}$. Although this was not statistically significant ( $p$-value of 0.10 ), it does indicate that the laser can be an effective curing unit. Despite the fact that it was not a shorter curing time, the laser does offer some advantages. The blue light diode laser has an output wavelength of $474 \mathrm{~nm}$ and this makes it more efficient because it does not produce the unwanted wavelengths. These unwanted wavelengths can produce additional heat, affecting the kinetics of the reaction and may thereby influence the reaction (Knezevic et al., 2007). In Knezevic's degree of conversion was achieved during sample polymerization.

Another point to note is that even though the laser cured samples for 5 seconds were lower than the LED sample at 10 seconds ( $p$-value $3.57 \times 10^{-6}$ ), the bond strengths were still within the clinically acceptable range. As previously mentioned, Reynolds stated that 5.9-7.8 MPa gave an acceptable bond strength and it was found that 5 seconds of curing with the blue light diode laser was 7.69 $\mathrm{MPa}$. A finding in this study that was unusual was that all bond strengths that were achieved with the LED cured samples were fairly similar, despite that amount of curing time. The average shear-peel bond strengths ranged from 11.00-11.91 MPa for curing times ranging from 3-10 seconds. A possibility for 
this could be that the light intensity was high enough that the LED light cured the adhesive adequately, even at much reduced curing times.

In the second part of this study, the results show a slight negative trend in shear-peel bond strength as the distance of the laser curing source increased. At $3 \mathrm{~mm}$ distance, which is approximately as close as the curing tip could get to the bracket-adhesive-tooth interface, the measured bond strength for 10 seconds of cure time was $13.09 \mathrm{MPa}$. With increasing distances, the bond strengths were 11.17 MPa and 10.23 MPa for $6 \mathrm{~mm}$ and $10 \mathrm{~mm}$, respectively. These values, however, were not statistically significant ( $p$-value of 0.22 ). Despite the fact that the values did decrease slightly, this was in accordance to what was expected as it was hypothesized that curing distance with the blue light diode laser should have no effect on shear-peel bond strength. This was expected due to the property that laser beams are collimated (Harris, Pick, 1995). A collimated beam indicates that there is very little divergence of the beam over distance, and that it will maintain its intensity and energy. The slight negative trend could again be explained by the beams small diameter. As the curing distance increases, it becomes increasingly more difficult to focus the beam directly on the desired location at the bracket-adhesive-enamel interface. Something that could help improve this is using a laser with a larger beam diameter or using a beam expander as suggested by Jang et al. (2009)

Concurring with the trends seen with the laser, the LED sample's shearpeel bond strength decreased significantly with increasing distance. The bond strength that was recorded with the tip of the LED curing unit 3mm away from the 
bracket-adhesive-enamel surface was $11.83 \mathrm{MPa}$ and as the distance was increased to 6 and $10 \mathrm{~mm}$, the bond strength dipped to 8.82 and $6.64 \mathrm{MPa}$, respectively ( $p$-value of $<0.0001)$. This was the result that was expected because light follows the inverse square law. Basically stated, as the distance from light source increases, the light intensity will decrease proportional to the square of the distance. The total light energy will remain the same; however it will be dispersed over a larger area. For example, in this study, when the curing tip distance was changed from 3 to $6 \mathrm{~mm}$, the light intensity decreased 9 times $\left(3^{2}=9\right)$ per unit area. Similar results were found for samples that were cured for 5 seconds over varying distances of 3,6 , and $10 \mathrm{~mm}$.

The location of bond failure was determined with the use of the adhesive remnant index (ARI). In the sample studying the changes in curing time, the highest level of enamel fracture was found in the LED cured sample for10 seconds (13.3\% of the teeth). It should be noted that the 4 teeth that showed enamel fractures in the first part of this study did not have exceptionally high shear-peel bond strengths. The bond strengths for the teeth with enamel fractures had bond strengths ranging from 6.53-9.77 $\mathrm{MPa}$. This is peculiar because one would expect to see enamel fractures in teeth that would have exceptionally high shear-peel bond strengths, as was noted by Retief in teeth at or above 13.7 MPa (Retief, 1974). These enamel fractures were clearly not due to high bond strengths, they could have been a result of desiccation of the teeth. Although great care was taken to store the teeth in a $0.1 \%$ Thymol solution when not being worked on, it is possible that they could have been desiccated following 
extraction or while being bonded. Another possibility could be micro-fractures of the enamel that could have occurred by the forceps during extraction.

The samples that had lower average shear-peel bond strengths (Blue light diode curing at 5 and 3 seconds of curing), expectedly had more teeth where the adhesive failed to bond with the enamel. ARI scores of 0 or 1 indicates that a minimum of $50 \%$ of the resin did not remain on the tooth upon debonding of the bracket. Laser curing at 5 seconds had $40 \%$ of its sample score an ARI score of 1 or lower, while Laser cured samples for 3 seconds had $66.7 \%$ of its sample score a 0 or 1 on the ARI. As previously mentioned, this result was expected because adhesive that is not polymerized completely will form a weak bond with the enamel surface. It should be noted that the Pearson Chi Squared Test Statistic only yielded a 16.39 with a p-value of 0.174 which was not statistically significant for a difference between groups.

In the second part of this study, a Pearson Chi-squared Test Statistic was again employed to check for difference between groups. For the samples that were cured for 10 seconds had a Pearson Chi-squared test statistic of 21.72 and for the samples cured for 5 seconds was 23.51, which gave statistically significant $p$-values of 0.041 and 0.024 respectively. The blue light diode laser group at all of the curing tip distances showed strong bonding between the enamel and adhesive. In the groups that were cured for 10 seconds, $100 \%$ of the teeth had ARI scores of 2 or 3 when the curing tip was $3 \mathrm{~mm}$ away from the curing surface. Even at 6 and $10 \mathrm{~mm}$ curing tip distance for the blue light diode laser, $90 \%$ of the teeth had ARI scores of 2 or 3 . ARI scores of 2 indicate that 
greater than $50 \%$ of the adhesive remained on the tooth surface, while an ARI score of 3 shows that all of the resin remains on the tooth surface. ARI scores of 2 or 3 indicate that a strong bond was formed between the enamel and adhesive. For LED curing units, the ARI scores tended to be on the lower side of the ARI scores for samples cured at the greater distances of 6 and $10 \mathrm{~mm}$.

There are some limitations to consider in this study. The aforementioned beam diameter most likely played a very large role in the results of this study. Jang et al (2009) describe the use of a beam expander which increased their beam diameter to $6 \mathrm{~mm}$. Although this diameter is still not as large as what is found on most commercially available LED curing units (most tend to have a diameter of $8 \mathrm{~mm}$ ), it could potentially have a drastic influence in achieving higher bond strengths. Another potential limitation of this study could be the inability to control the light intensity of the blue light diode laser. The intensity of the laser beam was measured at $610 \mathrm{~mW} / \mathrm{cm}^{2}$. Increasing the blue light diode lasers light intensity may produce higher bond strengths at shorter curing times.

Despite the fact that the blue light diode laser had reduced shear-peel bond strengths at shorter curing times, it still has a great deal of potential to be a high-quality curing unit. Future studies can focus on lasers that can produce a higher light intensity as well as a larger diameter beam. One of the most promising areas to investigate would be the reduced caries susceptibility of enamel after lasing with the blue light diode laser. Although, the caries resistance effect has been documented with other lasers, it has not been studied with the blue light diode laser. If it is found that lasing the enamel with the blue 
light diode laser imparts the properties of caries resistance, then the blue light diode laser could become the gold standard for curing units even if it cannot cure faster than LED's. 


\section{CHAPTER V}

\section{CONCLUSIONS}

1. At reduced curing times ( 3 and 5 seconds) with the blue light diode laser, shear-peel bond strengths decreased significantly when compared to the control group of LED curing with 10 seconds of curing time.

2. Although shear-peel bond strengths decreased by $35 \%$ for blue light diode lasers with a 5 second curing time compared to LED's with 10 second curing times, the bond strength achieved (7.69 MPa) was still in the clinically acceptable range outlined by Reynolds (5.9-7.8 MPa).

3. When the curing tip distance to the bracket-resin-enamel junction was increased from 3 to $10 \mathrm{~mm}$, the blue light diode laser still produced high shear-peel bond strengths. A statistically significant difference was not found when the curing tip of the blue light diode laser was increased from $3 \mathrm{~mm}$ to $10 \mathrm{~mm}$ from the curing surface.

4. Increasing the curing tip distance from 3 to $10 \mathrm{~mm}$ with the LED curing unit, shear-peel bond strengths dropped off dramatically. The shear-peel bond strength decreased from $11.83 \mathrm{MPa}$ at $3 \mathrm{~mm}$ down to $6.64 \mathrm{MPa}$ at $10 \mathrm{~mm}$ curing tip distance. 


\section{REFERENCES}

Althoff $\mathrm{O}$, Hartung M. Advances in light curing. American Journal of Dentistry. 2000; 13: 77D-81D

Artun J, Bergland S. Clinical trials with crystal growth conditioning as an alternative to acid-etch enamel pretreatment. Am J Orthod. 1984 Apr; 85(4):33340.

Barghi N, Berry T, Hatton C. Evaluating intensity output of curing units in private dental offices. J Am Dent Assoc 1994; 25: 992-996

Bassiouny MA, Grant AA. A visible light-cured composite restorative. Clinical open assessment. Br Dent J. 1978 Dec 5;145(11):327-30.

Bayne, SC., Heymann, HO, Swift EJ Jr. Update on dental composite restorations. J Am Dent Assoc. 1994, 125(6): 687-701

Birdsell DC, Bannon PJ, Webb RB. Harmful effects of near-ultraviolet radiation used for polymerization of a sealant and a composite resin, J Am Dent Assoc. 1977 Feb;94(2):311-4.

Bishara SE, VonWald L, Laffoon JF, Warren JJ. Effect of a self-etch primer/adhesive on the shear bond strength of orthodontic brackets. Am J Orthod Dentofacial Orthop, 2001; 119: 621-624

Blankenau RJ, Kelsey WP III, Powell GL, Shearer GO, Barkmeier WW, Cavel WT. Degree of composite resin polymerization with visible light and argon laser. American Journal of Dentistry, 1991; 4(1): 40-42

Buonocore, MG (1955) A simple method of increasing the adhesion of acrylic filling materials to enamel surfaces, Journal of Dental Research, 34, 849-853

Cerveira GP, Berthold TB, Souto AA, Spohr AM, Marchioro EM. Degree of conversion and hardness of an orthodontic resin cured with a light-emitting diode and a quartz-tungsten-halogen light. Eur J Orthod. 2010 Feb;32(1):83-6. 
Cobb DS, Dederich DN, Gardner TV. In vitro temperature change at the dentin/pulpal interface by using conventional visible light versus argon laser. Lasers Surg Med, 2000; 26: 386-397

Cobb DS, Vargas MA, Rundle T. Physical properties of composites cured with conventional light or Argon Laser. American Journal of Dentistry, 1996; 9(5): 199-202

Craig, $\mathrm{R}$, Composition and properties of composite resins, Dent. $\mathrm{Cl}$ of NA Saunders, Apr. 1981, Pg 229

Duncan Y, Powell GL, Higuchi WI, Fox J. Enhancement of Argon Laser effect on Disolution and loss of Human Enamel. J Clin Laser Med Surg. 1993; 11(5): 259261

Eliades T, Brantley WA. The inappropriateness of conventional orthodontic bond strength assessment protocols. Eur J Orthod. 2000; 22: 13-23

Forsten, L. Curing depth of visible light-activated composites. Acta Odontol Scand $1984 ; 42: 23-28$

Fox NA, McCabe JF, Buckley JG. A critique of bond strength testing in orthodontics. Br J Orthod. 1997; 21: 33-43

Fox JL, Yu D, Otsuka M, Higuchi WI, Wong J, Powell GL. Initial dissolution rate studies on dental enamel after CO2 laser irradiation. J Dent Res. 1992 Jul;71(7):1389-98.

Frentzen M, Koort HJ. Lasers in dentistry: new possibilities with advancing laser technology? Int Dent J. 1990 Dec;40(6):323-32.

Haitz RH, Crawford MG, Weissman RH. Light emitting diodes. Handbook of optics. $2^{\text {nd }}$ Ed., New York: McGraw Hill Inc, 1995, PG. 12.1-12.39

Harris DM, Pick RM. Laser physics. In: Miserendino LJ, Pick Rm, eds. Lasers in Dentistry. Chicago, IL: Quintessence; 1995: 27-38

Hildebrand NKS, Raboud DW, Heo G, Nelson AE, Major PW. Argon laser vs conventional visible light-cured orthodontic bracket bonding: An in-vivo and invitro study. American Journal of Orthodontics and Dentofacial Orthopedics, 2007; 131(4): 530-536

James JW, Miller BH, English JD, Tadlock LP, Buschang PH. Effects of highspeed curing devices on shear bond strength and microleakage of orthodontic brackets. Am J orthod Dentofacial Orthop. 2003; 123: 555-561 
Jang CM, Seol HJ, Kim HI, Kwon YH. Effect of Different Blue light-curing systems on the Polymerization of Nanocomposite Resins. Photomedicine and Laser Surgery, 2009; 27(6): 871-876

Katona TR, Moore BK. The effects of load misalignment on tensile load testing of direct bonded orthodontic brackets: a finite element model. Am J Orthod Dentofacial Orthop. 1994; 105: 543-551

A - Kelsey WP III, Blankenau RJ, Powell GL, Barkmeier WW, Cavel WT, Whisenant BK. Enhancement of physical properties of resin restorative materials by laser polymerization. Lasers in Surgery and Medicine, 1989; 9(6): 623-627.

Klocke A, Kahl-Nieke B. Effect of debonding force direction on orthodontic shear bond strength. Am J Orthod Dentofacial Orthop. 2006; 129: 261-265

Knezevic A, Ristic M, Demoli N, Tarle Z, Music S, Negovetic Mandic V. Composite Photopolymerization with Diode Laser. Operative Dentistry, 2007; 32(3): 279-284

Koupis NS, Eliades T, Athanasiou AE. Clinical evaluation of bracket bonding using two different polymerization sources. Angle Orthod. 2008 Sep;78(5):922-5.

Lalani N, Foley TF, Voth R, Banting D, Mamandras A. Polymerization with the Argon Laser: curing time and shear bond strength. Angle Orthodontist, 2000; $70(1): 28-33$

Meyer GR, Ernst CP, Willershausen B. Decrease in power output of new lightemitting diode (LED) curing devices with increasing distance to filling surface. $J$ Adhes Dent. 2002; 4:197-204

Nelson SJ, Berns MW. Basic laser physics and tissue interactions. Contemporary Dermatology. 1988; 2: 1-15.

Newman, GV, Facq, JM. The effects of adhesive systems on tooth surfaces, American Journal of Orthodontics, 1971; 59: 67-75

Noel L, Rebellato J, Sheats RD. The effect of Argon Laser Irradiation on Demineralization Resistance of Human Enamel adjacent to Orthodontic Brackets: an in vitro study. The Angle Orthodontist, 2003; 73(3): 249-258

Park YA, Chae KH, Rawis HR. Development of a new photoinitiation system for dental light-cure composite resins. Dental Materials, 1999; 15(2): 120-127

Pollack, BF, Blitzer, MH. The advantages of Visible Light Curing Resins, NYS Dental Journal, 1982; 48(4): 228-230 
Powell GL, Anderson JR, Blankenau RJ. Laser and curing light induced in vitro pulpal temperature changes. J Clin Laser Med Surg, 1999; 17: 3-5

B - Powell GL, Kelsey WP, Blankenau RJ, Barkmeier WW. The use of an Argon Laser for Polymerization of Composite Resin. Journal of Esthetic Dentistry, $1989 ; 1(1): 34-37$

Retief, DH (1973) Adhesion in Dentistry, Journal of Dental Association of South Africa, 28: 11-24

Retief DH. Failure at the dental adhesive-etched enamel interface. J Oral Rehabil 1974; 265-284

Reynolds, IR (1975) A review of Direct Orthodontic Bonding, British Journal of Orthodontics, 2(3): 171-178

Rode KM, Kawano Y, Turbino ML. Evaluation of curing light distance on resin composite microhardness and polymerization. Oper Dent. 2007 NovDec;32(6):571-8.

Rueggeberg FA, Jordan DM. Effect of light-tip distance on polymerization of resin composite. International Journal of prosthodontics, 1993; 6(4): 364-370

Rueggeberg FA, Twiggs SW, Caughman WF, Khajotia S. Life-time intensity profiles of 11 light-curing units. J Dent Res 1996; 75: 380

Ruyter IE, Oysaed $\mathrm{H}$. Conversion in different depths of ultraviolet and visible light activated composite materials. Acta Odontol Scand. 1982;40(3):179-92

Sognnaes R, Stern R. Laser effect on Resistance of Human Dental Enamel. Journal - Southern California Dental Association, 1965; 33: 328-329

Stabholz A, Zeltser R, Sela M, Peretz B, Moshonov J, Ziskind D, Stabholz A. The use of lasers in dentistry: principles of operation and clinical applications. Compendium of Continuing Education in Dentistry; 2003 Dec; 24(12): 935-948

Stahl F, Ashworth SH, Jandt KD, Mills RW. Light-emitting diode (LED) polymerisation of dental composites: flexural properties and polymerisation potential. Biomaterials 2000; 21: 1379-1385

Sulewski JG. Historical Survey of Laser Dentistry. Dent Clin North Am. 2000; 44: 717-752

Swartz ML, Phillips RW, Rhodes, B. Visible light-activated resins - depth of cure. Journal of American Dental Association. 1983; 106: 634-637 
Talbot TQ, Blankenau RJ, Zobitz ME, Weaver AL, Lohse CM, Rebellato J. Effect of Argon Laser Irradiation on Shear Bond Strength of Orthodontic Brackets: an in vitro study. American Journal of Orthodontics and Dentofacial Orthopedics, 2000; 118(3): 274-279

Wang, WN, Meng CL. A study of bond strength between light-and self-cured orthodontic resin. American Journal of orthodontics and dentofacial orthopedics. 1992, 101(4): 350-354.

Wilson HJ, Resin-based restoratives, Br Dent J. 1988 May 21;164(10):326-30. 


\section{CURICULUM VITAE}

NAME: $\quad$ Kamran Shaikh

ADDRESS: 9313 Springbrooke Circle

Louisville, KY 40241

DOB: $\quad$ Montreal, Quebec, Canada - August 31, 1978

EDUCATION

\& TRAINING: B.Sc., Human Biology

University of Toronto

1997-2001

DDS, Doctor of Dental Surgery

New York University College of Dentistry

2001-2005

General Practice Residency

University of Louisville, Department of Surgical and Hospital

Dentistry

2005-2006

Certificate in Orthodontics

University of Louisville Department of Orthodontics

2008-2010

AWARDS: Department of Orthodontics Honors Program

New York University College of Dentistry

2004

Dental Scholarship

New York University College of Dentistry

2001-2005

New College Student Council In-Course (OSOTF) Scholarship

The University of Toronto

2000 
Award of Excellence, Fifth Place

Connaught Student Biotechnology Exhibition

1997

PROFESSIONAL SOCIETIES:

American Association of Orthodontists Southern Association of Orthodontists Kentucky Association of Orthodontists American Dental Association

\section{PUBLICATIONS:}

J. Kermalli, O. El-Mowafy, W. El-Badrawy, B. Shokati, O. Soliman, F. Rajwani, R. Zawi, A. Encioiu, K. Shaikh. A survey of efficacy of QTH light curing units used in dental offices in Toronto - Light intensity. J Dent Res 82 (Spec Iss B) 2003

R. Zawi, W. El-Badrawy, O. El-Mowafy, O. Soliman, J. Kermalli, B. Shokati, F. Rajwani, A. Encioiu, K. Shaikh. A survey of efficacy of QTH light curing units used in dental offices in Toronto Heat/glare. J Dent Res 82 (Spec Iss B) 2003

O. Soliman, O. El-Mowafy, W. El-Badrawy, B. Shokati, J. Kermalli, F. Rajwani, R. Zawi, A. Encioiu, K. Shaikh. A Survey of Efficacy of QTH Light Curing Units Used in Dental Offices in Toronto - Curing Time Vs. Relative Hardness. J Dent Res 82 (Spec Iss B) 2003

B. Shokati, W. El-Badrawy, O. El-Mowafy, O. Soliman, J. Kermalli, R. Zawi, F. Rajwani, A. Encioiu, K. Shaikh. A Survey of Efficacy of QTH Light Curing Units Used in Dental Offices in Toronto Relative Hardness of a Resin Composite. J Dent Res 82 (Spec Iss B) 2003

F. Rajwani, W. El-Badrawy, O. El-Mowafy, J. Kermalli, O. Soliman, R. Zawi, B. Shokati, A. Encioiu, K. Shaikh. A Survey of Efficacy of QTH Light Curing Units Used in Dental Offices in Toronto Comparison with Tel Aviv, Texas and Tokyo. J Dent Res 82 (Spec Iss B) 2003

WORK EXPERIENCE: General Dentist James F. Bennett, DDS, PSC 2009-2010 
General Dentist

Cincinnati Dental Services

2006-2008 